\title{
The Relationship between Economic Growth and the Environmental Quality in the Huaihe River Basin
}

\author{
Xianze Peng, Zichen Zhou \\ Hubei University of Technology, Wuhan 430068, China
}

\begin{abstract}
Keywords: the Huaihe River basin; EKC curve; Economic growth; Environmental quality
Abstract: Based on the theory of EKC curve, industrial waste water, industrial waste gas emissions (take $\mathrm{SO}_{2}$ as a representative) and industrial solid waste are selected as the environmental indicators. GDP per capita is used as economic indicators. According to the Huaihe River in five provinces in 2004-2014 panel data of economy and environment, the Huaihe River in economic growth and the relationship between the ecological environment quality was established between per capita GDP and industrial "three wastes" model, and Eviews software system is used. The results showed that: The Huaihe River in the period of study, the five provinces of per capita GDP is the trend of increased year by year, basic industrial wastewater, industrial emissions, discharge of industrial solid waste and environmental pollution index were higher; Except for industrial waste gas pollution began to appear under the comprehensive control of partial improvement, the remaining basic rise. Therefore, in order to realize the Huaihe River basin of the coordinated development of economy and environment must follow the recycling economy, take a new road to industrialization.
\end{abstract}

\section{Problem description and literature review}

Propose the problem

Huaihe River basin is the earliest comprehensive management of rivers after the founding of new China. In recent years, the Huaihe River basin is in the economic transition. With the rapid development of industrialization, the contradiction between the economy and the natural environment is increasingly highlighted ${ }^{[1]}$. The party's 18th put forward overall well-off and "two double" strategic goals to improve the economic growth of endogenous power and trying to build for our country the third out her golden channel of the Huaihe River. To accelerate the construction of ecological economic zone of the Huaihe River basin, make it an important strategic fulcrum of economic growth. How to realize the coordinated development of economy and environment in the Huaihe River basin has become a hot issue.

Literature review

The relationship between economic growth and the environment in recent years has become the common problem faced by human society sustainable development. The empirical study of western scholars on the relationship between economy and environment began in the early 1990s. Grossman and Krueger (1991) the first empirical study on the relationship between the economy and environment, and find the relationship between economic growth and environmental quality change curve "inverted U" characteristics. In the initial stage of economic development, the degree of environment pollution is light, and with the further growth of economy, environmental pollution aggravate; When it reaches to a certain level of economic development, environmental pollution will be slowed instead and improved gradually. Panayotou (1993) consider this curve and economists Kountze, per capita income level and the degree of distribution justice in research relations between the proposed Kountze kuznets curve similar to that of the relationship between economic growth and environmental quality are presented in the "inverted U" curve called Kountze environment kuznets curve (EKC). Jie He (2007) summarized the reason that different research object on the relationship between the economic growth and environmental quality by showing a different curve shape. He considered that selects samples from different time span, different 
environment and economic indicator variables and different measurement test model will lead to different shape Kathleen.

The statistical data about the environmental pollution in our country and the research about the relation between economic growth and environmental quality come relatively late. Yunhong Gao, Meichang Wang (2011) build the economy of the environmental quality index, using the variance decomposition method of Jiangxi province in 1987-2008 to study the relationship between economic growth and environmental quality, verifying it conforms to the characteristics of EKC curve. Jihong Ding Yan Nian (2010) took Jiangsu province as the research object, using principal component analysis (pca) to analyze the six categories of environmental pollution and established comprehensive pollution index structure composed of pollution and the output of the simultaneous equation. It proved that Jiangsu province has "N" type curve characteristics between economic growth and environmental quality.

According to the statistical of 2004-2014 data, this article adopted three environmental indicators and economic indicators, using Eviews software to econometric analysis and to explore if the Huaihe River basin existing EKC curve characteristics between economic growth and environmental quality. By analyzing the relationship between the two, clarify the Huaihe River basin economic development and environmental protection win-win to provide scientific theory basis. But due to the availability of data, the provincial statistics caliber is not very consistent, which may have influence on concrete numerical value in final results.

\section{Present situations of economy and environment in Huaihe River basin}

Economic development situations

China is an agricultural country; agriculture has a very important status and is also a traditional advantage industry in Huaihe River basin. From 2004 to 2014, the economic development of the Huaihe River basin are going along with the increase of the output value of agriculture, and the proportion is on the decline, which also marks the economic development level Huaihe River is improving ${ }^{[2]}$. Added value of agriculture in 2014 is nearly 6 trillion yuan, but with the development and progress, it led to resources consumption and serious environmental pollution at the same time. As is known to all, the Huaihe River valley is rich in natural resources, most of them are non-renewable. With the needs of economic development, these resources will one day be unused, and by late pollution control is a very difficult.

The present situation of environment

The economic development model in Huaihe River basin is basically "high investment, low efficiency, high emission"[3]. Based on resource advantage, it gives priority to heavy chemical industry, and the extensive mode of production comes with high resource consumption and serious environmental pollution. The excessive exploitation of groundwater resources in some cities around Huaihe River basin has caused deep city levee ecological environment problems such as sinking. Population expansion, resulting in destroying forest and vegetation damage, soil erosion, land desertification, eventually causing agricultural output decreases. Huaihe River basin comes into a vicious cycle of economy, and the regional ecological environment problem has become an important factor of social and economic sustainable development.

\section{Model selection, data source and the empirical process}

\section{Model selection}

There have been a lot of researches about the influence of economic development on environment quality both at home and abroad scholars. This article selects two forms of curve (EKC) model to empirical study:

$$
\begin{aligned}
& Y_{i t}=\alpha_{i}+\beta_{1} X_{i t}+\varepsilon_{i t} \\
& Y_{i t}=\alpha_{i}+\beta_{1} X_{i t}+\beta_{2} X_{i t}{ }^{2}+\varepsilon_{i t}
\end{aligned}
$$


It generally uses a type, quadratic form, and usually the simplest model to obtain better fitting results. In the two models above, explained variable $Y$ for environmental indicators, $Y_{\text {it }}$ on behalf of the pollution emissions (discharge) in i province in the $\mathrm{t}^{\text {th }}$ year. Explaining variable $\mathrm{X}$ for economic indicators, $X_{\text {it }}$ on behalf of the per capita GDP in i province in $t^{\text {th }}$ year ${ }^{[4]}$. $\varepsilon_{\text {it }}$ presents other variables affecting the quality of environment. $\alpha_{\mathrm{i}}$ is the cross section effect; $\beta_{\mathrm{i}}$ is the coefficient of explaining variable. As the effect of cross section, explain the variable coefficient. The empirical results show that EKC in the industrialized countries will present a more obvious three forms, while developing countries are not (Poonetal., 2006) ${ }^{[5]}$. China is in the early stage of industrial transformation development. Therefore the first choice is the primary and secondary form of EKC, and when there exist certain disadvantages to the quadratic form, three models to improve again is considered. blow:

There are several kinds of relationship between economic growth and environmental quality

(1) $\beta_{1}=\beta_{2}, \beta_{2}=0$ : There is no relationship between economic growth and environmental quality;

(2) $\beta_{1}>0, \beta_{2}=0$ : Environmental quality linear increase along with the growth of the economy;

(3) $\beta_{1}<0, \beta_{2}=0$ : Environmental quality linear decrease along with the growth of the economy;

(4) $\beta_{1}>0, \beta_{2}<0$ : Environmental quality and economic growth is "inverted U" relationship;

(5) $\beta_{1}<0, \beta_{2}>0$ : Environmental quality and economic growth is " $U$ " relationship. Index selection

This article selects 2004-2014 as the index data. The per capita GDP in the five provinces of the Huaihe River basin have realized the rapid growth and overall increase the proportion of industry rapidly in this period ${ }^{[5]}$. Because the Huaihe River in five provinces is still in the development stage of industrialization, industry is still a driving force to promote the development of its economy, the industrial "three wastes", namely, waste water, waste gas and solid waste emissions of maximum stress the quality of environment of the region, so the three are chosen as environmental indicators. Per capita GDP is selected to measure the indexes of the regional economic development level; the unit is RMB one hundred.

The source of data

Three indicators of environmental quality data come from China environment statistical yearbook 2004-2014. Economic growth indicators (GDP) data come from China statistical yearbook from 2003- 2013 and relevant provincial statistical yearbook.

\section{The empirical results and analysis of Huaihe River basin environmental}

The empirical results

According to the setting of EKC model according, model (1), (2) are chosen for five provinces of the Huaihe River basin in 2004-2014 economic and environmental quality index. Before doing the data regression analysis, HAUSMAN test is used to select the fixed effects model or random effects model. And according to the HAUSMAN test results, it select fixed effects model ${ }^{[6]}$. After comparing coefficient of the results of model analysis, it concluded that: model (1) is chosen for industrial waste water (FS), model (2) is chosen for industrial waste gas $\left(\mathrm{SO}_{2}\right)$ and industrial solid waste (GF).

Table 1. Waste water, waste gas $\left(\mathrm{SO}_{2}\right)$,industrial solid waste fixed effects model.

\begin{tabular}{cccc}
\hline Model index & FS & SO $_{2}$ & GF \\
\hline $\mathrm{C}$ & 120761.8 & 1055326 & -129.7303 \\
$\beta_{1}$ & 157.7199 & 362.9141 & 65.2009 \\
$\beta_{2}$ & - & -0.897677 & -0.083037 \\
Adjusted-R ${ }^{2}$ & 0.832799 & 0.912021 & 0.952053 \\
$\mathrm{~F}$ & 13.31639 & 94.29675 & 60.5688 \\
\hline
\end{tabular}

Through GLS measurement results, we can get the fitting equation between industrial "three wastes" emissions and per capita GDP : Equation (3), (4), (5); the corresponding curve respectively is shown in figure 1,2 and 3. 


$$
\begin{aligned}
& Y=120761.8+157.7199 X \\
& Y=1055326+362.914 X-0.89767 X^{2} \\
& Y=-129.7303+65.2009 X-0.083037 X^{2}
\end{aligned}
$$

From the above description about characteristics of EKC curve, observing parameters of GLS regression results in model, combining with the relationship between economic growth and environmental pollution fitting curves, we can conclude:

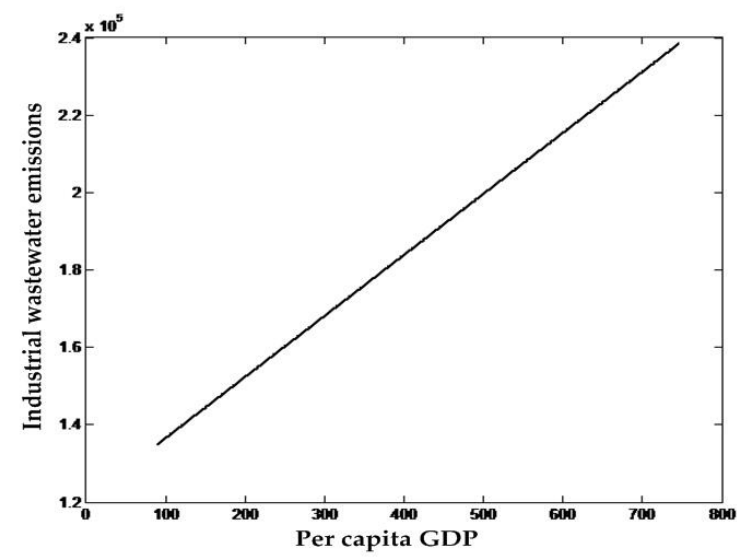

Figure 1. Fitting curve of industrial waste water emissions and the per capita GDP in the Huaihe River region

(1) Industrial wastewater emissions linearly increase with the increase of per capita GDP, and no presence of the typical characteristic of the "inverted U". This shows that during the study period, the industrialization of Huaihe River basin is in acceleration stage, and provinces pay attention to the development of the industry. While related management department haven't get a good effect for the discharge, supervision and management of industrial wastewater. With the development of economic, per capita GDP grows rapidly, which lead to the rising industrial wastewater emissions, and environmental pressure is much bigger ${ }^{[6]}$.

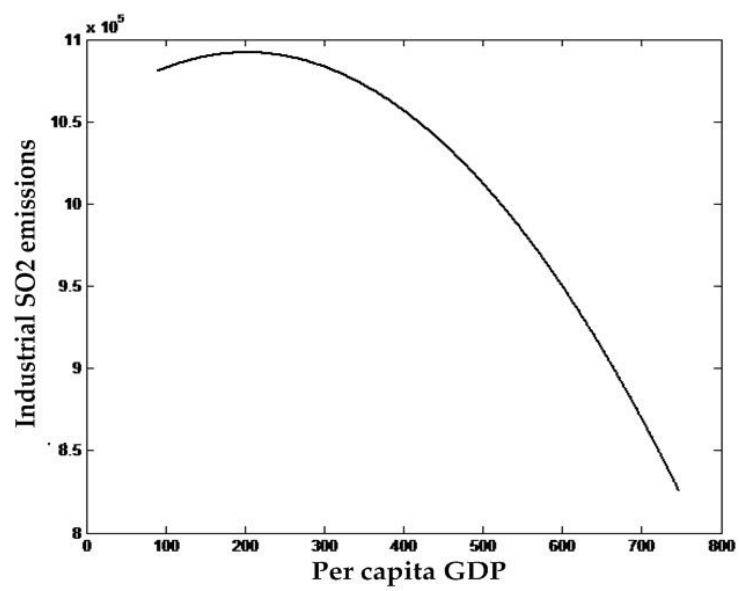

Figure 2. Fitting curve of industrial waste gas $\left(\mathrm{SO}_{2}\right)$ emissions and the per capita GDP in the Huaihe River region

(2) There is a typical characteristic of the "inverted U" curve between industrial emissions $\left(\mathrm{SO}_{2}\right)$ and per capita GDP. It comes to the turning point when per capita GDP reaches 20000 yuan. Look at selected data of Huaihe River basin in five provinces, In previous years of study period, the per capita GDP in most of the provinces are less than 20000 yuan, then more than 20000 yuan. This suggests that with the development of economy, industrial emissions increase at first, then decrease. It also suggests that at the first stage of study period, the Huaihe River basin is in early industrialization, along with the economic development, the provincial per capita GDP grow; Industrialization is also 
led to the industrial waste gas emissions continue to increase. While in the latter stages of the study period, the CPC Central Committee, State Council and governments at all levels to increase along the Huaihe River pollution control and supervision of industrial emissions the Huaihe River Basin, which has considerably reduced the industrial gas emissions, and then achieved certain results.

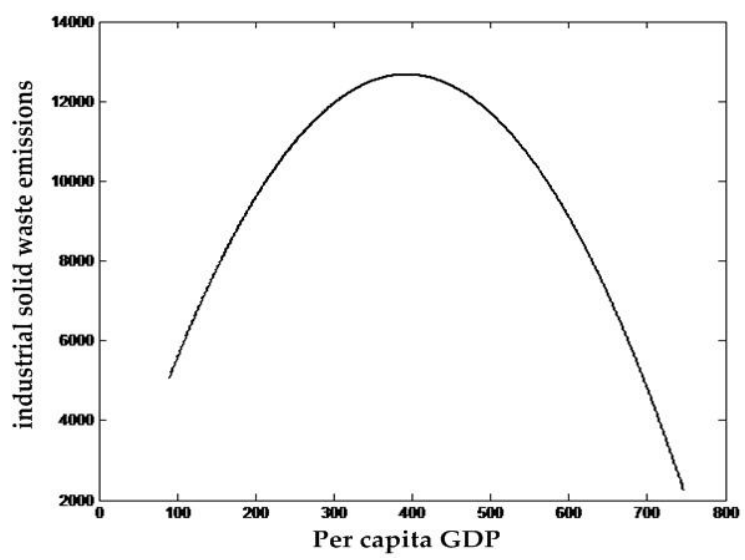

Figure3. Fitting curve of industrial solid waste emissions and the per capita GDP in the Huaihe River region

(3) There is typical environmental Kuznets curve characteristic of the "inverted U" in industrial solid waste and per capita GDP. The turning point comes when per capita GDP reaches 40000 yuan. In the context of the selected data, Shandong and Jiangsu's per capita GDP are more than 40000 yuan and 70000 yuan, after 2010, and all other provinces in the study period almost haven't reached this level of 40000 yuan. This suggests that with the growth of the GDP per capita, per capita presents ascendant trend at the beginning of the study period. What matches the reality is that industries of Huaihe River basin mainly depend on coal, electric power, textile and other heavily polluting industries, including chemical industry, mining high pollution ${ }^{[7]}$, which leads to the production of industrial solid waste in the rapid rise. Countries in recent years for prevention and control policy have begun to pay off, but with the growth of economy, environmental pressure is still large.

\section{Conclusions and policy recommendations}

\section{Conclusions}

Through the above analysis, it is easy to see: during the study period, GDP per capita in the five provinces of the Huaihe River presents the trend of increased year by year, basically environmental pollution index are higher ${ }^{[8]}$; In Huaihe River basin ecological environmental quality of the relationship between per capita GDP and the fitting curve, in addition to industrial waste gas pollution began to appear under the comprehensive control of partial improvement, the remaining basic rise. This shows that environment pollution levels are rising with the rapid economic growth at the same time.

Policy suggestions

In Huaihe River basin in 2004-2004, this study examines the relationship between economic growth and environmental quality on the basis of empirical research, draw the relevant conclusions and put forward the following relevant policy recommendations.

Increase environmental protection money

A country in the process of rapid economic development must have come up with a certain amount of money used in environmental protection career. According to the experience of developed countries: a country in the high-speed economic development, if the environmental protection investment accounted for $1 \%$ to $5 \%$ of GDP, which can effectively control the pollution of the environment; Only when the environmental investment to GDP ratio of 3\%, the ecological environment quality can be improved ${ }^{[8]}$. But from the research of Huaihe River basin in five provinces in 2004-2014 investment in environmental protection career, while there are certain investment, but that was needed to improve the environment of the environmental protection 
investment GDP gap is still large. So should increase investment in environmental protection funds, improve the ecological environment of the Huaihe River basin, and insist for a long time.

Intensify environmental protection law enforcement

The influencing factors on the quality of the environment is complex and diverse, in addition to the national economy level, also include other factors such as social, natural, and, in particular, the role of environmental law enforcement to protect the ecological environment is more direct and effective. Under high pressure environment policy in recent years, for example, the Huaihe River basin in emissions, to a certain extent, improve the worsening environmental problems. Control of Huaihe River industrial "three wastes" emissions, increase pollution control investment and implementation of the project, depend on the further improvement of the environment protection policy and the Huaihe River basin environmental protection law enforcement.

Requires optimization of industrial structure, the new road to industrialization of circular economy

Huaihe River industry with energy, building materials, food, textile, leather and other industries is given priority to, these large industrial resources consumption and environmental pollution is serious. Huaihe River basin is relatively single industrial structure, industrial enterprise technical level is low, the lack of modern high technology industry. On the one hand, the government actively the implementation of pollutant discharge fee system, strictly control the industrial enterprises of all kinds of pollutant emissions; Industrial enterprises to increase investment in science and technology, and, on the other hand, using the new technologies, new processes, new equipment to modernize traditional industry, optimize the industrial structure, reduce the various emissions of pollutants, to realize the harmonious development of economy and environment of the Huaihe River basin, a new road to industrialization of circular economy.

\section{References}

[1] Xiao Zhang. Overall evaluation of China's environmental policy. Social Sciences in China 1999, 21(3),88-99.

[2]Wenjing Zhang. Thinking about the development of Huaihe River basin ecological environment sustainable. Environmental Protection 2011,04, 41-42.

[3]Dongxia Li, Yujie Yang. Twenty years the study of the relationship between economic growth and environmental quality in hubei province. Journal of Hubei Engineering University 2011, 05, 114-118. [4]Yan Liu. The empirical study on the relationship between economic growth and environmental quality. Jiangxi University of Finance and Economics, 2012.

[5]Lailun Wan, Junfeng Zhu, Dianmei Shen. River basin economic growth and the relationship between ecological environment quality changes ---from 1998-2007 years experience in the huaihe River in Anhui. Areal Research and Development 2009, 04, 125-128+138.

[6]Pinghui Zhu, Jiajun Yuan, Wuyi Zeng. China's industrial environmental kuznets curve analysis, empirical research based on spatial panel model. China Industrial Economics 2010, 06, 65-74.

[7]Chunmao Xiong, Min Chen. Hanjiang basin thinking of sustainable utilization of water resources of hubei province. Water Resources Development Research 2013, 04, 34-38.

[8]Jiang Qin, Bangyan Feng. Economic growth space differentiation in a River basin, based on the Yangtze River basin from 2001 to 2009 panel data econometric analysis. Resources and Environment in the Yangtze Basin 2012, 11, 1308-1313.

\section{This paper is the supported by following projects:}

Ministry of education of humanities and social science research special tasks project (honghu wetland red culture education in ideological and political education research path); Wuhan Institute of open issues; Circular economy development research center (HXFkY1510) 